\section{Processos de interdição: família, direito e medicina fabricando capacidades $e$ incapacidades}

Alexandre ZARIAS. Negócio público e interesses privados: a interdição civil e os dramas de familia. São Paulo, Hucitec/Anpocs, 2005. 269 páginas.

\section{Ana Lúcia Pastore Schritzmeyer}

Dispensa elogios um livro com a chancela do "Prêmio José Albertino Rodrigues" - melhor dissertação de mestrado no Concurso CNPq-Anpocs de Obras Científicas e Teses Universitárias em Ciências Sociais (edição 2004) -, prefaciado por Heloísa Pontes - orientadora do autor em seu mestrado em antropologia social na Unicamp - e apresentado por Sérgio Adorno - seu atual orientador no doutorado em sociologia da USP. Portanto, sendo redundante, assinalo se tratar de uma pesquisa da mais alta qualidade metodológica, temática e bibliográfica.

Sem dúvida, minhas apreciações e percepções do trabalho de Alexandre têm a marca da empatia decorrente do fato de termos formações e trajetórias acadêmicas semelhantes, além de interesses temáticos comuns. Como ele, freqüentei, simultaneamente, graduações em ciências sociais e em direito, prossegui no mestrado em antropologia social estudando relações entre medicina e direito ${ }^{1}$ e já compartilhei, com Sérgio Adorno, a execução de várias pesquisas no NEV - Núcleo de Estudos da Violência da USP. Mas é justamente essa afinidade que também me coloca em posição de leitora crítica e especialmente atenta aos caminhos escolhidos pelo pesquisador, tanto ao recortar como ao analisar a problemática elaborada.

Começo pela precisa escolha bibliográfica e o ótimo uso que Alexandre faz dos principais autores com os quais dialoga - Goffman, Bourdieu, Foucault, Castel, Cicourel e Mauss, entre outros. Em especial, alguns conceitos de Goffman, como os que embasam sua teoria situacional do desvio carreira, impropriedades situacionais (situational improprieties) e unidades de interação -, perpassam os cinco capítulos dando-lhes a consistência de quem soube, com maturidade e criatividade intelectuais, mesclar, na devida medida, referências teóricas e dados provenientes de fontes judiciais, entrevistas e trabalho de campo etnográfico.

É na "Introdução", por sinal, que Alexandre, logo de chofre, lança o leitor no que há de mais íntimo e rico em um material de pesquisa antropológico: anotações do diário de campo. De forma perspicaz e bem humorada, é descrita uma diligência em que juíza, promotora e escrevente, além do próprio pesquisador, foram à casa de uma interditanda para proceder a um interrogatório. Esse "tom etnográfico", resultante de observações de interrogatórios, de perícias médicas e dos trabalhos realizados nos cartórios judiciais em que os dados foram coletados, é retomado, em vários outros momentos do texto, sempre com o cuidado de enfatizar os limites de quaisquer estratégias metodológicas e, conseqüentemente, as riquezas provenientes de possíveis combinações entre elas.

Ainda na "Introdução", é resumido o tema central do livro - a interdição -, de modo a se compreender como funciona, no Brasil, esse mecanismo legal de natureza civil pertencente à área do direito de família. Nessa oportunidade, Alexandre apresenta claramente a espinha dorsal de seu estudo: processos de interdição como espaço privilegiado de interseções e negociações de sentidos entre as esferas da família, da justiça e da medicina. Sua problemática revela-se de modo preciso: analisar esse espaço de encontros e desencontros entre múltiplos e distintos olhares, todos voltados para a pessoa do interditando e preocupados em classificar seus comportamentos por meio das noções de "doença" e "incapacidade civil". O mapeamento da dinâmica das relações entre esses representantes das instituições familiar, jurídica e médica, em função dos esforços classificatórios que cada um faz em face dos interditandos, é o desafio que o pesquisador enfrenta.

É ainda nessa abertura do livro que o autor explicita o amadurecimento de seu projeto de mestrado a partir de pesquisas dos tempos de graduação, dos primeiros contatos com arquivos históricos e judiciários de Campinas e dos três anos cursados em direito. 
As dificuldades encontradas na coleta de dados em arquivos judiciários - localização dos processos, imprecisões dos livros de registros, greves do Poder Judiciário - estão bem pontuadas, assim como as influências desses obstáculos e de sua superação sobre os critérios adotados na seleção do material.

Por fim, os capítulos são apresentados e é mencionada, pela primeira vez, a novela de Honoré de Balzac, $A$ interdição (1836), como fonte de inspiração analítica. Fechando a "Introdução", a estrutura do livro é comparada à descrição de um jogo, com suas regras, objetivos, jogadas possíveis e mais freqüentes, movimentos e estratégias de jogadores e equipes. Lamentei esse insight comparativo não ter ido além de um uso metafórico, pois enriqueceria ainda mais o trabalho a exploração do conceito de jogo como elemento essencial à cultura, tal como o faz o filósofo Johan Huizinga em seu livro Homo ludens, no qual aprofunda, inclusive, a relação entre jogo e Direito (cap. 4). ${ }^{2}$ Tal relação, por exemplo, constituiu-se um dos caminhos teóricos fundamentais de meu doutorado em antropologia social, no qual analisei sessões de julgamento pelos cinco Tribunais do Júri da cidade de São Paulo como rituais lúdicos e teatralizados. ${ }^{3}$

$\mathrm{Na}$ primeira parte do Capítulo 1, o autor familiariza os leitores com os termos legais referentes à interdição e, ao destacar, nesse tipo de processo, a importância das noções de "doença" e "capacidade civil", argumenta, com muita propriedade, a respeito do poder dos médicos determinarem o que é normal e patológico, assim como o dos juízes definirem o que é legal e ilegal. Nos casos de interdição, esses profissionais, por intermédio de suas instituições e discursos oficiaiscompetentes, fabricam as noções de "doença" e de "capacidade civil", atualizando-nas a cada vez que decidem que todo incapaz é doente, embora somente alguns tipos de doentes sejam incapazes.

$\mathrm{Na}$ segunda parte, é apresentado um estudo de caso realizado a partir de um dos processos de interdição selecionados, o qual exemplifica como os documentos judiciais e periciais cristalizam significados tensamente negociados entre as instituições familiar, médica e judicial. Ao reproduzir parcialmente alguns desses documentos, Alexandre analisa a relatividade das categorias "doença" e "capacidade civil", uma vez que seus alcances resultam de um conjunto de práticas sociais jamais unívocas. Assim, nomes de "doenças" variam de acordo com as negociações estabelecidas entre os diferentes saberes reunidos nos processos e em função de disputas no interior de um mesmo saber, como é o caso de variadas definições de "loucura" conforme a tradição das "escolas médicas". Surge, portanto, nessa arena, não só a "doença" como fenômeno sociológico, mas também o interditando como ponto nodal entre os vários discursos que a ele se dirigem e contribuem para a construção de sua carreira de incapaz-doente, de doente-capaz ou de saudável-capaz. Nas palavras de Alexandre: "No processo de interdição, [...] podemos não só acompanhar parte da trajetória de vida de uma pessoa, mas também podemos apreender parte das instituições com as quais essa pessoa se envolveu" (p. 77).

No Capítulo 2, o autor cria categorias para descrever o universo de interdições, partindo de características dos participantes das ações judiciais e da forma como direito e medicina reagem às demandas de familiares de interditandos. Nesse ponto, chamou-me a atenção o dado de que grande parte dos processos de interdição se vale da justiça gratuita e obedece a uma requisição do INSS, pois esse instituto necessita de decisões dessa natureza para garantir a regularização de outros benefícios, como aposentadoria por invalidez, pensão por morte e auxílio ao deficiente. Outra parte dos processos é motivada por requisições do próprio Tribunal para que seja possível o andamento de processos referentes, por exemplo, a direitos sucessórios.

Tais dados me fizeram pensar na pesquisa que atualmente desenvolvo, no sul da Bahia, com alguns colegas de Portugal. ${ }^{4}$ Trata-se de uma investigação sobre significados e negociações familiares, cartoriais e legais envolvidos na composição e no registro oficial de prenomes e sobrenomes de pessoas da região. Uma das conclusões preliminares a que chegamos, após lermos vários "processos de retificação de nome", foi a de que, especialmente nos muitos casos em que aparentemente se discute "apenas" a inserção ou a exclusão da preposição "de" (Maria do Socorro ou Maria Socorro? José da Silva ou José Silva?), o que está em jogo é a necessidade, diante do INSS, de a pessoa regularizar seus documentos para garantir o recebimento de benefícios. Quero, com isso, chegar ao seguinte 
ponto: parece que o Estado, a partir de suas próprias instituições (INSS, Poder Judiciário), mantém suas engrenagens funcionando quase que por conta própria. Lembrando Kafka, processos geram processos, funcionários públicos criam trabalho para outros funcionários públicos e, nesse sem fim de burocracias, para a sorte de cientistas sociais, valores e significados de relações de parentesco, vizinhança, compadrio etc. restam registrados nas linhas e entrelinhas de documentos oficiais.

Essa espécie de autofuncionamento e auto/inter-regulação das instituições do Estado, mesmo não sendo uma das preocupações centrais do trabalho de Alexandre, nele aparece em várias passagens, tanto que uma das principais motivações apontadas para as interdições é a de natureza burocrática-instrumental, em que o interditando se vê em meio a um redemoinho de requisições interinstitucionais para regularizar certos direitos. Porém, outras motivações, desvinculadas de demandas burocráticas e relacionadas a interesses mais propriamente familiares, também são apontadas como relevantes e, ao enumerá-las, o pesquisador dá vOZ aos "nativos" (funcionários de cartórios, juízes, promotores, peritos médicos, interditandos), valendo-se de suas próprias categorias para compreendê-los. Ao classificarem os processos de interdição segundo "tipos", destacam-se os interesses patrimoniais geralmente envolvidos nas interdições, tornando-se os bens materiais dos interditandos objeto de disputa entre seus familiares.

Outro aspecto analítico importante desse capítulo está na menção, ainda que relativamente rápida, à disputa entre operadores do Direito e peritos médicos por posições decisórias no jogo processual. Quem dá a última palavra? Como os jargões são reciprocamente lidos, compreendidos ou incompreendidos? E como, afinal, esses profissionais se compõem (ou não) nas decisões? Lembrei-me de outros trabalhos que também abordam esse tema e penso na potencialidade desse filão para novas pesquisas em ciências sociais. ${ }^{5}$

$\mathrm{Na}$ última parte do Capítulo 2, encontramos dois quadros e algumas tabelas que, apesar de seguidos de comentários um pouco áridos e descritivos, demonstram-se fundamentais nos capítulos posteriores, uma vez que funcionam como visões panorâmicas e bem articuladas do conjunto de processos selecionados, tanto segundo tipos (Quadro
1, pp. 90-91) como segundo efeitos, os quais permitem classificar as "agências" como "de encaminhamento" ou "de controle" (Quadro 2, p. 109). No primeiro caso, reúnem-se as interdições cujos desfechos, apesar de modificarem direitos e deveres do interditado, não alteram seu papel familiar, uma vez que ele já assume a posição de "doente". No segundo caso, há modificações de direitos e deveres, além de o papel familiar do interditado passar a ser o de doente, transferindo-se, geralmente para alguém da família, o controle de seu patrimônio e de sua pessoa.

O tratamento metodológico e analítico dado às categorias desses quadros está muito bem feito e a estratégia narrativa de iniciar cada capítulo com uma breve retomada do anterior, além de uma antecipação do que nele será desenvolvido, favorece a amarração e a compreensão do conjunto do trabalho. Nessa linha, o Capítulo 3 começa com a retomada do segundo e o anúncio de que a novela de Balzac - A interdição - foi inspiradora por condensar os principais temas em jogo: relação entre (in)capacidade civil, doença e inadequação de comportamentos sociais (desvios).

Valendo-se bastante de Goffman, o texto flui consistente ao apontar a força normatizadora da gramática legal como responsável por uniformizar acontecimentos díspares, pois, ao narrá-los, transforma-os em padronizados fatos jurídicos. Reportando-se a importantes trabalhos de pesquisadoras brasileiras, como Mariza Corrêa e Joana Vargas, Alexandre enfatiza as normas jurídicas como produtoras de rótulos, de interpretações, de papéis familiares e mesmo de pessoas doentes e sãs. Ao citar autores das áreas da psiquiatria e psicologia social, o texto prossegue, crescendo em profundidade analítica, rumo à proposta de relacionar literatura e antropologia. A novela de Balzac é, então, detidamente retomada e seu "caráter paradigmático" é destacado, à medida que ela desvenda o "circuito de relações internas e externas ao processo de interdição" e ordena descritivamente "fatos dispersos no tempo numa narrativa que segue a ordem dos ritos processuais" (p. 140). O capítulo termina com mais um quadro profícuo (Quadro 3, p. 141), no qual é esboçado o percurso analítico norteador do restante do texto.

O penúltimo capítulo é dedicado à descrição dos papéis desempenhados por advogados, juízes, promotores e médicos em cada etapa processual e 
tem por base as principais peças por eles produzidas nesse ritual - petição inicial, termo de interrogatório, laudo pericial e sentença. Para tanto, são apresentados casos e situações de pesquisa, mesmo que ainda sem desfecho à época da finalização da coleta de dados, o que, apesar de deixar o leitor curioso, não prejudica as análises desenvolvidas, pois interessam menos os casos, em si, e mais seus contextos (situações de interação), bem como sua força exemplificativa no conjunto dos processos analisados. A metáfora do "jogo" é novamente utilizada para mencionar o desenrolar do processo como um conjunto de estratégias de fabricação e negociação de papéis entre os envolvidos; papéis esses que podem variar conforme ocasiões, lugares e modos de condução dos encontros.

As instituições e a interdição constituem o eixo que Alexandre explora, no último capítulo, ao apresentar mais três casos envolvendo "doença mental”, patrimônio, negócios, deveres de mãe, alcoolismo e vizinhança. Neles, os discursos médico e jurídico absorvem as falas dos participantes; a igreja substitui a família em meio às relações junto à justiça e à medicina; e, por fim, uma família inteira é, pouco a pouco, identificada como "anormal".

Realmente, Alexandre Zarias, como ele mesmo afirma nas "Considerações finais", foi além (e muito) de um estudo apoiado somente em compêndios de medicina, códigos legais e processos jurídicos. Foi plenamente atingido seu objetivo de compreender a interdição "como um encontro de instituições que, de forma ritualizada, negociam categorias de identidade [...]" (p. 249). Seu livro é rico em análises e exemplos da diversidade simbólica contida nas relações entre pares de opostos como, por exemplo, "doença-incapacidade civil/ saúdecapacidade civil", cujos sentidos, sempre relativos, multiplicam-se nos processos de interdição.

É, sem dúvida, um ganho para as literaturas antropológica e sociológica, em especial as da antropologia e sociologia jurídicas, a publicação do mestrado de Alexandre, pois, com toda razão, ele finaliza seu livro chamando a atenção para o quão pouco explorada é a área do direito civil nos estudos sobre a organização da justiça brasileira.

Quando conheci pessoalmente Alexandre, na VI Reunión de Antropología del Mercosur RAM, em Montevidéu, Uruguai (novembro de
2005), ocasião em que apresentamos nossas atuais pesquisas no mesmo grupo de trabalho - GT 43: "Violência de gênero e violência intrafamiliar" -, fiquei muito interessada por sua abordagem sociojurídica de família à luz das mudanças do Novo Código Civil (2003), no qual essa instituição não mais é diretamente definida, porém indiretamente regulamentada por aspectos pertinentes ao casamento, união estável, relação entre pais e filhos, separação de casais etc. É, portanto, com muito entusiasmo que aposto na continuidade de suas pesquisas e em diálogos que possamos estabelecer a respeito da justiça brasileira - "palco de encontro entre categorias do senso comum com as ditas técnicas oficias", como bem conclui Alexandre, no último parágrafo do livro.

\section{ANA LÚCIA PASTORE SCHRITZMEYER é professora do Departamento de Antropologia da Faculdade de Filosofia Letras e Ciências Humanas da Universidade de São Paulo (FFLCH-USP).}

\section{Notas}

1 Ana Lúcia Pastore Schritzmeyer, Sortilégio de saberes: curandeiros e juízes nos tribunais brasileiros (1900-1990), São Paulo, IBCCRIM, 2004.

2 Johan Huizinga, Homo ludens: o jogo como elemento da cultura, São Paulo, Perspectiva, 1980.

3 Ana Lúcia Pastore Schritzmeyer, Controlando o poder de matar: uma leitura antropológica do Tribunal do Júri - ritual lúdico e teatralizado, São Paulo, Tese de doutorado, Faculdade de Filosofia, Letras e Ciências Humanas da USP, 2002.

4 Nomes e cores: nomeação pessoal e complexidade identitária na Babia. Pesquisa coordenada por João de Pina Cabral. Financiamento: Fundação para a Ciência e Tecnologia do Ministério da Ciência e Ensino Superior de Portugal. Apoio: Universidade de São Paulo (Pró-Reitoria de Pesquisa - Projeto 1). Início: outubro de 2004; término previsto: outubro de 2007.

5 Ver, por exemplo, Magali Engel, Meretrizes e doutores: saber médico e prostituição no Rio de Janeiro (1840-1890), São Paulo, Brasiliense, 1989; Martha de Abreu Esteves, Meninas perdidas: os populares e o cotidiano do amor no Rio de Janeiro da Belle Époque, Rio de Janeiro, Paz e Terra, 1989; e Ana Lúcia Pastore, 2004, op. cit. 